\title{
Complex systems for corpus linguists
}

\section{William A. Kretzschmar, Jr University of Georgia and Uppsala University}

In recent years the field of corpus linguistics has become more and more reliant on statistics. Our professional meetings commonly have papers that feature computational approaches like neural networks and Hidden Markov Models, and that claim to be conducting machine learning or sentiment analysis or text mining or topic modeling. While labels that talk about learning or sentiment or mining or topic models are really metaphors designed to attract our interest, the statistics are real enough. While real, they may not give results that are easy to interpret. With so-called Black Box methods, users put the textual data from a corpus into a statistic like a neural network and an answer always comes out, but what the answer tells us is not clear (humanists may recall similar doubt about prophecies from the Oracle at Delphi or Cassandra at Troy). As an article about the use of neural networks on language variation points out (Kretzschmar 2008), the statistic did not discover regional patterns in the variation data as the analysts intended but instead self-organized the data into a different, unexpected range of categories. Neural networks and other Black Box methods may be excellent examples of mathematical skill, and still not tell us much about questions of language use.

Under these circumstances it behooves the corpus linguist to know more about the distributions of data from corpora. These distributions arise from the complex system of human speech. Language is not just a 'bag of words' as a term from natural language processing suggests, but instead has reliable underlying patterns that we can use to make judgments about authors, works, genres, and other issues of interest. These are not the usual patterns of grammar but frequency profiles of words and other variants, which are always nonlinear and scale-free. This essay will explain complex systems (CS), and then suggest how a knowledge of complex systems can help us in our analyses. CS affects corpus creation with either a whole population or with random sampling, and affects quantitative methods used in corpus analysis. CS tells us why 'normal' statistics will not work well with corpora, and suggests how to use the assumption of non- 
linear distributions and scaling to talk about document identification and comparison of language in whole-to-whole or part-to-whole situations like authors or text types (sometimes referred to as genres or registers). As we shall see, the CS model matches in detail with what corpus linguists already know about their data, and it offers a way to understand distributional patterns that have in the past seemed problematic.

In Mitchell's (2009:13) definition, a complex system is "a system in which large networks of components with no central control and simple rules of operation give rise to complex collective behavior, sophisticated information processing, and adaptation via learning or evolution." The new science of complex systems, also known as complex adaptive systems or complex physical systems, got off the ground in 1984, when the Santa Fe Institute was founded for its study. CS received early allusive discussion in linguistics: Lindblom, MacNeilage, and Studdert-Kennedy published a 1984 paper on self-organizing processes in phonology; Paul Hopper presented his seminal paper called "Emergent grammar" in Berkeley in 1987; Ronald Langacker published a chapter on "A usage-based model" for cognitive linguistics in 1988. The essays in Ellis and Larsen-Freeman suggest how CS may be involved in language learning. Work by Joan Bybee $(2001,2002)$ promoted the importance of word frequency and eventually mentioned CS (2010). Three recent books, however, have embraced CS and developed ideas about it much more fully. Kretzschmar (2009) has demonstrated how complex systems do constitute speech in The linguistics of speech, focusing on nonlinear distributions and scaling properties. Kretzschmar (2015), Language and complex systems, applies CS to a number of fields in linguistics. Finally, Burkette 2016, Language and material culture: Complex systems in human behavior, applies CS to both the study of language and the anthropological study of materiality. There is also now an undergraduate textbook, Exploring linguistic science (Burkette and Kretzschmar 2018), that offers an easier pathway to introduce CS to linguists including chapters especially for corpus linguists.

The essential process of all CS can be summed up in just a few principles: 1) random interaction of large numbers of components, 2) continuing activity in the system, 3) exchange of information with feedback, 4) reinforcement of behaviors, 5) emergence of stable patterns without central control. CS were originally described and are still used in the physical and biological sciences (e.g. Prigogine and Stengers 1984; Hawking and Mlodinow 2010, Gould 2003), somewhat later in computer science (e.g. Holland 1998). CS in speech consists of randomly interacting variant realizations of linguistic features as deployed by human agents, speakers. Activity in the system consists of our conversations and 
writing. Human agents can choose how to deploy linguistic variants, and our implicit comparison of the use of different components by different speakers and writers contributes to the operation of feedback and reinforcement. That is, we speakers choose to use a particular variant, whether consciously or not, in response to what we hear from other speakers (feedback), and our choices build a quantitative pattern in all of our speech (reinforcement). The order that emerges in speech is simply the configuration of components, whether particular words, pronunciations, or constructions, that arises in the local communities, regional and social, and in the linguistic situations in speech and writing, text types, in which we actually communicate. All of this activity takes place given the contingencies of the time, the circumstances in the world that affect how people interact and what they need to talk about, which is how adaptation of language occurs in the CS of speech. Nonlinear frequency profiles (asymptotic hyperbolic curves, or A-curves) constitute the quantitative pattern that always emerges from reinforcement for linguistic features at every level. Some linguists will recognize these profiles as Zipfian. Moreover, A-curves emerge for an entire dataset and also for every subgroup in the data - but the order of elements in the profile (that is, the frequencies of all of the possible variants, in the order by which they are more or less common) is likely to differ between groups, and between any group and the overall dataset. This is a major difference from Zipf's Law, which just applies to words in a text (more about that below). Language change, adaptation, thus comes down to changes in frequency profiles, and the A-curve pattern is actually a data transformation (use of the frequency of all the variants at one time as opposed to a single variant over time) of the Scurve commonly discussed in historical linguistics. Complexity science thus defines the relationship between language in use and any generalizations we may wish to make about it. Thus, a knowledge of CS offers a much more powerful way to understand language, in all of its parts and in all of its text types and in all of its groups of speakers, than Zipf's observation about words in texts. CS addresses the perennial problem in linguistics of the contrast between language as a human behavior and language as system.

Figure 1 shows an example of what every corpus linguistics student quickly discovers. When we count the words in a text, here Huck Finn and A Farewell to Arms, we see the same distributional pattern, a few words with very high counts but rapidly decreasing counts on the list. We do not see nouns and verbs, adjectives and adverbs, at the top of the list but instead function words like determiners, prepositions, conjunctions, auxiliaries, and pronouns. As John Burrows has written, "they constitute the underlying fabric of a text, a barely visible web that gives shape to whatever is being said" (Burrows 2008). Words that we consider 
to be meaningful, content words, only start to occur much further down in the list, after 250 or so function words. The same pattern occurs when we make a whole corpus out of many different texts, as shown in Figure 1 at right in the word frequency list from the million-word Brown Corpus. So, corpus linguists immediately learn that the English words they care most about as meaningful in their language are not as common as the English words that hold the meaningful words together. While function words may be "a barely visible web," their exceptionally high frequency offers a first view of the stable structure of the lexicon. In English, a small number of words, about 250 of them, dominate the frequency pattern of words in the language, even if corpus linguists regularly get rid of them by using a stop list.

\section{HuckFinn}

1
2
3
4
5
6
7
8
9
10
11
12
13
14
15
16
17
18
19
20

$\begin{array}{ll}6361 & \text { and } \\ 4806 & \text { the } \\ 3663 & \text { I } \\ 3156 & \text { a } \\ 2942 & \text { to } \\ 2544 & \text { it } \\ 2123 & \text { 't } \\ 2068 & \text { was } \\ 1860 & \text { he } \\ 1652 & \text { of } \\ 1524 & \text { you } \\ 1440 & \text { in } \\ 1234 & \text { that } \\ 1119 & \text { 's } \\ 1037 & \text { but } \\ 964 & \text { so } \\ 961 & \text { we } \\ 888 & \text { on } \\ 862 & \text { up } \\ 856 & \text { all }\end{array}$

\section{FarewellToArms}

$\begin{array}{ll}6206 & \text { the } \\ 3841 & \text { I } \\ 3168 & \text { and } \\ 2264 & \text { to } \\ 2131 & \text { a } \\ 2015 & \text { you } \\ 1639 & \text { it } \\ 1448 & \text { was } \\ 1367 & \text { in } \\ 1225 & \text { said } \\ 1138 & \text { of } \\ 1077 & \text { we } \\ 913 & \text { he } \\ 899 & \text { 't } \\ 791 & \text { on } \\ 741 & \text { that } \\ 721 & \text { they } \\ 649 & \text { not } \\ 648 & \text { were } \\ 618 & \text { with }\end{array}$

\section{BrownCorpus}

$\begin{array}{ll}1 & 70002 \text { the } \\ 2 & 36472 \text { of } \\ 3 & 32003 \text { a } \\ 4 & 28935 \text { and } \\ 5 & 26239 \text { to } \\ 6 & 21422 \text { in } \\ 9 & 10789 \text { that } \\ 10 & 10102 \text { is } \\ 12 & 9815 \text { was } \\ 13 & 9797 \text { he } \\ 14 & 9499 \text { for } \\ 15 & 9093 \text { it } \\ 16 & 7291 \text { with } \\ 17 & 7253 \text { as } \\ 18 & 7000 \text { his } \\ 21 & 6766 \text { on } \\ 22 & 6387 \text { be } \\ 23 & 6288 \text { 's } \\ 24 & 5935 \text { I } \\ 25 & 5382 \text { at }\end{array}$

Figure 1: Word frequency in Huck Finn, A Farewell to Arms, and the Brown Corpus

When we turn our attention to meaningful content words like nouns, we find that they are not randomly dispersed across the language as optional elements in grammatical patterns. Each text type, or domain, has its own frequency profile for particular nouns. Figure 2 shows a listing of the top twenty nouns by frequency in the 'academic' section of the BYU Corpus of Contemporary American English (COCA, https://www.english-corpora.org/coca/, as viewed in April 2021, consisting of over a billion words gathered from 1990 to 2019; of course the numbers change as the monitor corpus grows each year). 


\begin{tabular}{|c|c|l|l|}
\hline 1 & $\square$ & STUDENTS & 227068 \\
\hline 2 & $\square$ & TIME & 141800 \\
\hline 3 & $\square$ & SCHOOL & 122062 \\
\hline 4 & $\square$ & STUDY & 121382 \\
\hline 5 & $\square$ & EDUCATION & 113807 \\
\hline 6 & $\square$ & RESEARCH & 110949 \\
\hline 7 & $\square$ & PEOPLE & 107438 \\
\hline 8 & $\square$ & CHILDREN & 100740 \\
\hline 9 & $\square$ & YEARS & 95053 \\
\hline 10 & $\square$ & DATA & 94347 \\
\hline 11 & $\square$ & WORLD & 90833 \\
\hline 12 & $\square$ & STATE & 86818 \\
\hline 13 & $\square$ & GROUP & 84322 \\
\hline 14 & $\square$ & HEALTH & 80689 \\
\hline 15 & $\square$ & INFORMATION & 77423 \\
\hline 16 & $\square$ & TEACHERS & 77089 \\
\hline 17 & $\square$ & WORK & 76240 \\
\hline 18 & $\square$ & WOMEN & 76160 \\
\hline 19 & $\square$ & DEVELOPMENT & 75025 \\
\hline 20 & $\square$ & USE & 74743 \\
\hline & & \\
\hline 19
\end{tabular}

Figure 2: Top 20 nouns, COCA Academic

The numbers under the 'academic' heading run from 227,068 for students at the top down to 74,743 for use at the bottom. So, when we are talking about aca- 
demic subjects, we can expect to use and hear these words frequently. In Figure 3 we see the top 28 words for the corpus overall.

\begin{tabular}{|c|c|c|c|c|c|c|c|c|c|c|c|}
\hline HELP & $?$ & & ALL & BLOG & WEB-GENL & TV/MOVIES & SPOKEN & FICTION & MAGAZINE & NEWSPAPER & ACADEMIC \\
\hline 1 & $\square$ & PEOPLE & 1707619 & 318038 & 267974 & 138749 & 415659 & 101645 & 167611 & 198660 & 99283 \\
\hline 2 & $\square$ & TIME & 1601568 & 236428 & 228079 & 232871 & 218237 & 200699 & 185038 & 162623 & 137593 \\
\hline 3 & $\square$ & WAY & 1066264 & 163441 & 148363 & 165626 & 161449 & 152288 & 116071 & 91908 & 67118 \\
\hline 4 & $\square$ & YEARS & 1017103 & 136505 & 131781 & 76935 & 153612 & 88610 & 155761 & 178846 & 95053 \\
\hline 5 & $\square$ & LIFE & 679447 & 95869 & 103849 & 100139 & 83905 & 82242 & 87317 & 62671 & 63455 \\
\hline 6 & $\square$ & WORLD & 678541 & 105582 & 114646 & 53575 & 77455 & 53124 & 101784 & 86059 & 86316 \\
\hline 7 & $\square$ & DAY & 665337 & 90617 & 89513 & 97742 & 96838 & 97284 & 84429 & 79557 & 29357 \\
\hline 8 & $\square$ & MAN & 665102 & 55141 & 73797 & 185470 & 85148 & 150487 & 47310 & 47961 & 19788 \\
\hline 9 & $\square$ & YEAR & 648697 & 100126 & 91629 & 7425 & 87036 & 34127 & 108310 & 172353 & 47691 \\
\hline 10 & $\square$ & THINGS & 604458 & 109431 & 94568 & 79775 & 127560 & 69906 & 54095 & 49673 & 19450 \\
\hline 11 & $\square$ & THING & 551285 & 84190 & 65234 & 135318 & 117139 & 70333 & 41778 & 37293 & \\
\hline 12 & $\square$ & SCHOOL & 474568 & 53031 & 53873 & 26507 & 41375 & 40753 & 38894 & 105973 & 114162 \\
\hline 13 & $\square$ & PRESIDENT & 438560 & 51142 & 60278 & & 207258 & & 32663 & 85140 & 2079 \\
\hline 14 & $\square$ & HOUSE & 432152 & 42459 & 49826 & 55297 & 92884 & 78693 & 45936 & 67057 & \\
\hline 15 & $\square$ & STATE & 414892 & 67617 & 78162 & & 48523 & & 35259 & 116024 & 69307 \\
\hline 16 & $\square$ & FAMILY & 411396 & 47718 & 50309 & 44738 & 62904 & 40637 & 58567 & 63595 & 42928 \\
\hline 17 & $\square$ & MONEY & 408460 & 72084 & 57751 & 65332 & 70701 & 34657 & 44085 & 61082 & 2768 \\
\hline 18 & $\square$ & CHILDREN & 395055 & 45461 & 51627 & & 54401 & 36547 & 54207 & 59527 & 93285 \\
\hline 19 & $\square$ & NIGHT & 392940 & 34053 & 35727 & 92729 & 59913 & 94881 & 36006 & 39631 & \\
\hline 20 & $\square$ & WOMEN & 385748 & 62907 & 53144 & & 53618 & 33150 & 66569 & 48131 & 68229 \\
\hline 21 & $\square$ & LOT & 384258 & 62593 & 44783 & 40783 & 129273 & 26339 & 33899 & 46588 & \\
\hline 22 & $\square$ & PART & 380862 & 63714 & 64969 & 4028 & 64191 & 32920 & 50265 & 51086 & 49689 \\
\hline 23 & $\square$ & PLACE & 377316 & 50217 & 53075 & 60053 & 42880 & 57180 & 42575 & 37568 & 33768 \\
\hline 24 & $\square$ & WORK & 374008 & 63943 & 66099 & 13688 & 31650 & 34981 & 53470 & 43458 & 66719 \\
\hline 25 & $\square$ & GOVERNMENT & 362777 & 65432 & 66240 & & 71186 & & 39985 & 62024 & 57910 \\
\hline 26 & $\square$ & MR & 359116 & 21110 & 33375 & 4310 & 131961 & 44005 & 821 & 122793 & 741 \\
\hline 27 & $\square$ & PERCENT & 346744 & 28120 & 38640 & & 58610 & & 61702 & 97506 & 62166 \\
\hline 28 & $\square$ & STUDENTS & 336920 & 28178 & 30477 & & 2272 & & 14737 & 42386 & 218870 \\
\hline
\end{tabular}

Figure 3: Top 28 words, COCA overall

The "all" heading gives the figures for the corpus overall. The highest frequency words there are people (with 170,7619 occurrences, compared to 99,283 in the academic section) and time (with 1,601,568 tokens compared to 137,593 in the academic section), and it is evident that the words are in a different order. The top ranked word in the Academic section, students, is only in rank 28 overall. Looking across the COCA eight subsections, the dark cells show in which subsections each word is most common. There are relatively few dark cells under 
the academic subsection, since Figure 3 selects the top-ranked nouns overall. By this measure, academic language appears to be quite different from the language in COCA overall.

The subsection most different from the academic section is fiction, and Figure 4 shows the top twenty noun list for fiction in COCA.

\begin{tabular}{|l|l|l|l|}
\hline 1 & $\square$ & TIME & 209454 \\
\hline 2 & $\square$ & MAN & 161541 \\
\hline 3 & $\square$ & WAY & 156050 \\
\hline 4 & $\square$ & EYES & 139633 \\
\hline 5 & $\square$ & HEAD & 116452 \\
\hline 6 & $\square$ & PEOPLE & 113976 \\
\hline 7 & $\square$ & ROOM & 110686 \\
\hline 8 & $\square$ & MOTHER & 110122 \\
\hline 9 & $\square$ & DAY & 109785 \\
\hline 10 & $\square$ & HAND & 109075 \\
\hline 11 & $\square$ & DOOR & 104555 \\
\hline 12 & $\square$ & FACE & 102327 \\
\hline 13 & $\square$ & NIGHT & 98851 \\
\hline 14 & $\square$ & FATHER & 94492 \\
\hline 15 & $\square$ & YEARS & 90506 \\
\hline 16 & $\square$ & HOUSE & 89575 \\
\hline 17 & $\square$ & LIFE & 86033 \\
\hline 18 & $\square$ & WOMAN & 81649 \\
\hline 19 & $\square$ & BACK & 75395 \\
\hline 20 & $\square$ & THINGS & 73286 \\
\hline
\end{tabular}

Figure 4: Top 20 nouns, COCA Fiction

Time, people, and years are the only three words shared with the top twenty list for the academic section. This tells us that the frequency profiles for the subsections can be quite different (as implied in Figure 3): each domain has its own, mostly different set of most frequent words. These frequency profiles tell us that there is indeed an underlying organizational pattern for nouns, that words are not randomly deployed in grammatical slots as suggested by the 'bag of words' notion from NLP. While any of the top twenty words from fiction could be used in other domains, they are usually less likely to be used there than they are in fiction. Part of what makes fiction sound right for us is that writers use the right words, the most frequent ones for the domain. The same is true of academic 
writing or of spoken language. Any domain will sound right to us when we see the right words used there.

We find the same thing when we go below the large headings in COCA and inspect smaller domains. Figure 5 shows the top twenty list for just the humanities section of COCA academic writings.

\begin{tabular}{|c|c|l|l|}
\hline 1 & $\square$ & MUSIC & 43129 \\
\hline 2 & $\square$ & STUDENTS & 26245 \\
\hline 3 & $\square$ & ART & 25565 \\
\hline 4 & $\square$ & TIME & 20494 \\
\hline 5 & $\square$ & WORK & 16091 \\
\hline 6 & $\square$ & EDUCATION & 14912 \\
\hline 7 & $\square$ & WORLD & 14870 \\
\hline 8 & $\square$ & WAY & 12880 \\
\hline 9 & $\square$ & ARTS & 12599 \\
\hline 10 & $\square$ & HISTORY & 12241 \\
\hline 11 & $\square$ & LIFE & 12236 \\
\hline 12 & $\square$ & PEOPLE & 11440 \\
\hline 13 & $\square$ & WOMEN & 10940 \\
\hline 14 & $\square$ & SCHOOL & 10863 \\
\hline 15 & $\square$ & CHILDREN & 10144 \\
\hline 16 & $\square$ & TEACHERS & 10094 \\
\hline 17 & $\square$ & CULTURE & 9899 \\
\hline 18 & $\square$ & STORY & 9619 \\
\hline 19 & $\square$ & LANGUAGE & 9530 \\
\hline 20 & $\square$ & YEARS & 8900 \\
\hline
\end{tabular}

Figure 5: Top 20 nouns, COCA academic: humanities

Some of the words are the same as the higher level of scale of the entire academic subsection, but nine new words have entered the humanities list: music, way, art, arts, life, history, language, story, and culture. Of course the order of words is different, too, besides having different words: school, people, and children, for example, are much further down on the list. And the order matters. As we see in the numbers at the right of Figure 5, moving down a few ranks on the list can make a huge difference in frequency, especially among the very top ranks. When students moved from first rank in the overall academic list to second rank in the humanities list, it is proportionately only about 60 percent as frequent as the top ranked word, music. The smaller domain, humanities, does not have the same set of most frequent words as the larger domain, academic writ- 
ing, of which it is a part, and the words that humanities writing shares with academic writing are in a different order. This means that we can recognize the right words for humanities writing separately from the right words for academic writing, even though humanities writing is a subset of academic writing. Moreover, although I will not illustrate it for you, we could inspect domains within the humanities like writing about music or writing about literature and find that they also had somewhat different words, and words in a different order, from the list at the level of humanities writing. Within literature, we could inspect the domain for just writing about medieval literature, or for just writing about modern literature, and the same thing would happen. The organization of words in a corpus, then, does not occur for the language overall or within a few large domains, but instead in an unlimited number of domains at different levels of scale. In every domain, at whatever level of scale, we will be able to find the most common words, the words that identify the special quality of the lexicon for that particular domain. This is the scale-free property of CS: while every subsection has a nonlinear, A-curve frequency profile, every subsection can be recognized for itself in its frequency order of items (here words). Thus, scale-free reinforcement from CS is the underlying property that allows a corpus linguist to compare whole to whole (Hemingway to Twain) or whole to part (Brown Corpus to Hemingway) or part to part (Academic to Fiction within COCA) and reliably find differences.

The area of mathematics that describes scale-free networks is called fractals. Fractal, nonlinear mathematics is difficult for most of us because it is not part of the usual mathematics training in western education, which focuses on simple operations and Euclidean geometry, perhaps going as far as calculus (the branch of mathematics that describes moving objects). Westerners are all trained to see the world in three dimensions - as in lines (one dimension), squares (two dimensions), and cubes (three dimensions) - while fractal objects have non-integer dimensions and so become less visible in the world around us. Yet the world is full of fractal objects like trees, snowflakes, and coastlines. Benoit Mandelbrot has written that "many patterns of Nature are so irregular and fragmented, that, compared to [standard geometry] Nature exhibits not simply a higher degree but an altogether different level of complexity" but that these patterns may still be described as a "family of shapes" that he called fractals (1982: 1). Fractal patterns, according to Mandelbrot, are self-similar at different scales, which is what the term "scale-free" indicates. These patterns also involve chance, so that not all trees look alike even though they have the same branching pattern - self similar, not identical. This is the problem with George Zipf's famous description of words in texts as a "law": it is not true that all distributions of words in texts 
exactly follow his formula, that the frequency of a word in a text is inversely proportional to its rank (so the that second-ranked word is half as frequent as the top-ranked word). The pattern is self-similar, not exactly repeating as it should be in a law like one from physics.

Our lists of words in domains have a different graphic appearance, not the branching of a tree but a nonlinear A-curve (Figure 6).

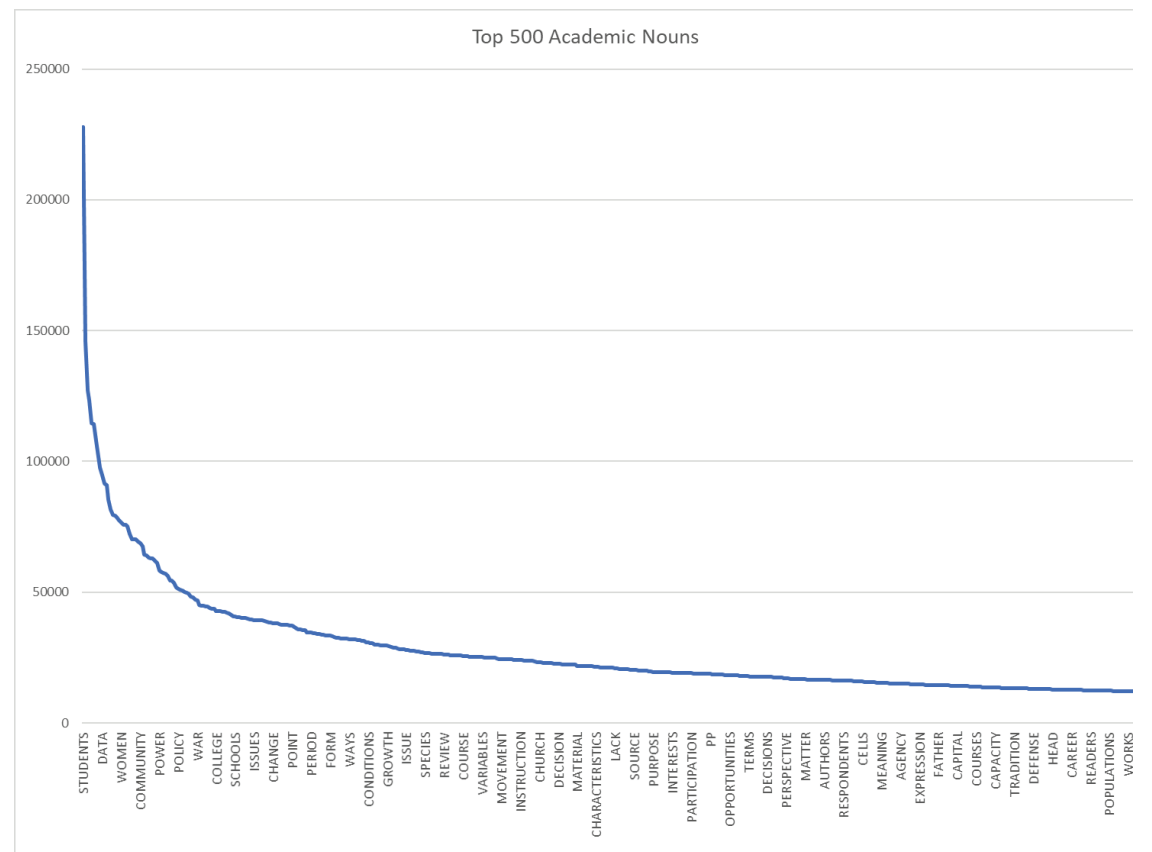




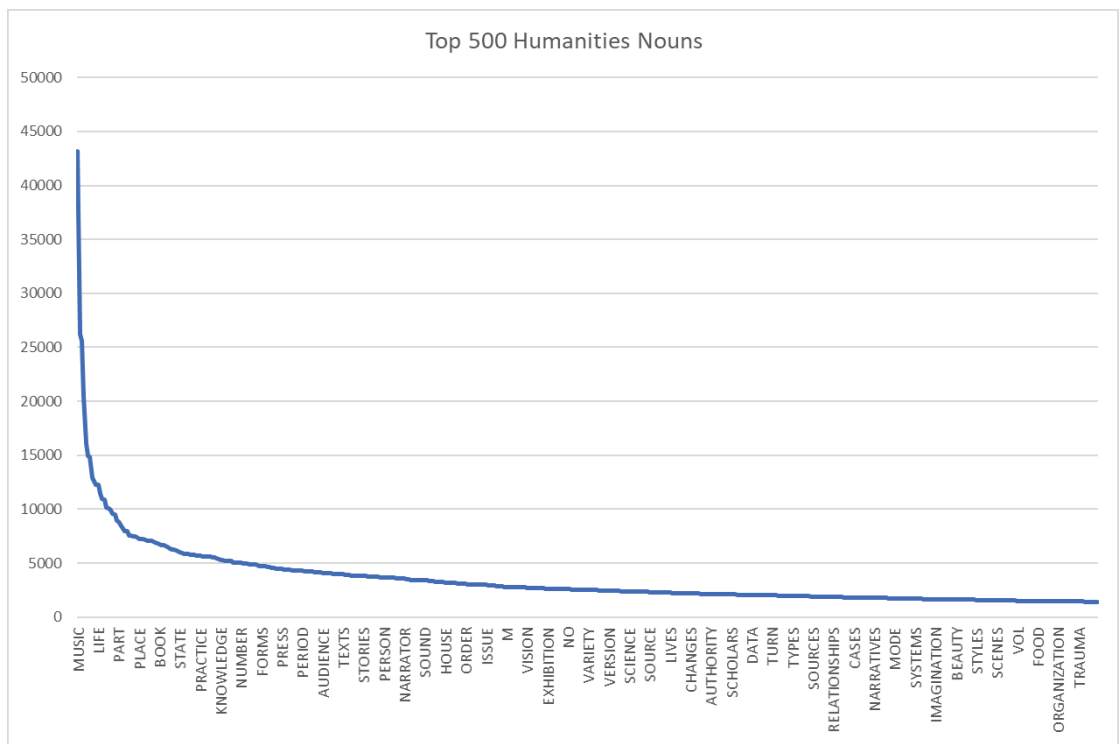

Figure 6: Scale-free nonlinear curves (A-curves)

Every set of words we have seen so far, whether the function words or the academic nouns or the fiction nouns or the humanities nouns, have a self-similar nonlinear pattern. The top-ranked word is much more common than the secondranked word, which is much more common than the third-ranked word, if not exactly in the proportion recommended by Zipf. In Figure 6 we see the nonlinear pattern for the top 500 academic nouns and for the top 500 humanities nouns. The curves have approximately the same shape. Even though the list of humanities nouns has different words in it than the academic nouns, and there is a different order of words in each list, the curves are the same. Thus the organizational pattern of words in a corpus is very regular, not random at all. The same frequency profile, the same A-curve, always describes the lexicon for any domain, even though the words themselves and the order of words on the list will be different for every domain. Again, this fractal pattern of scale-free nonlinear curves is the result of the operation of human speech as a complex system.

What does this do for all of us users of language, who participate in many different domains at different moments in our lives? There is a psychological effect of the universal underlying frequency pattern of our speech and writing. 


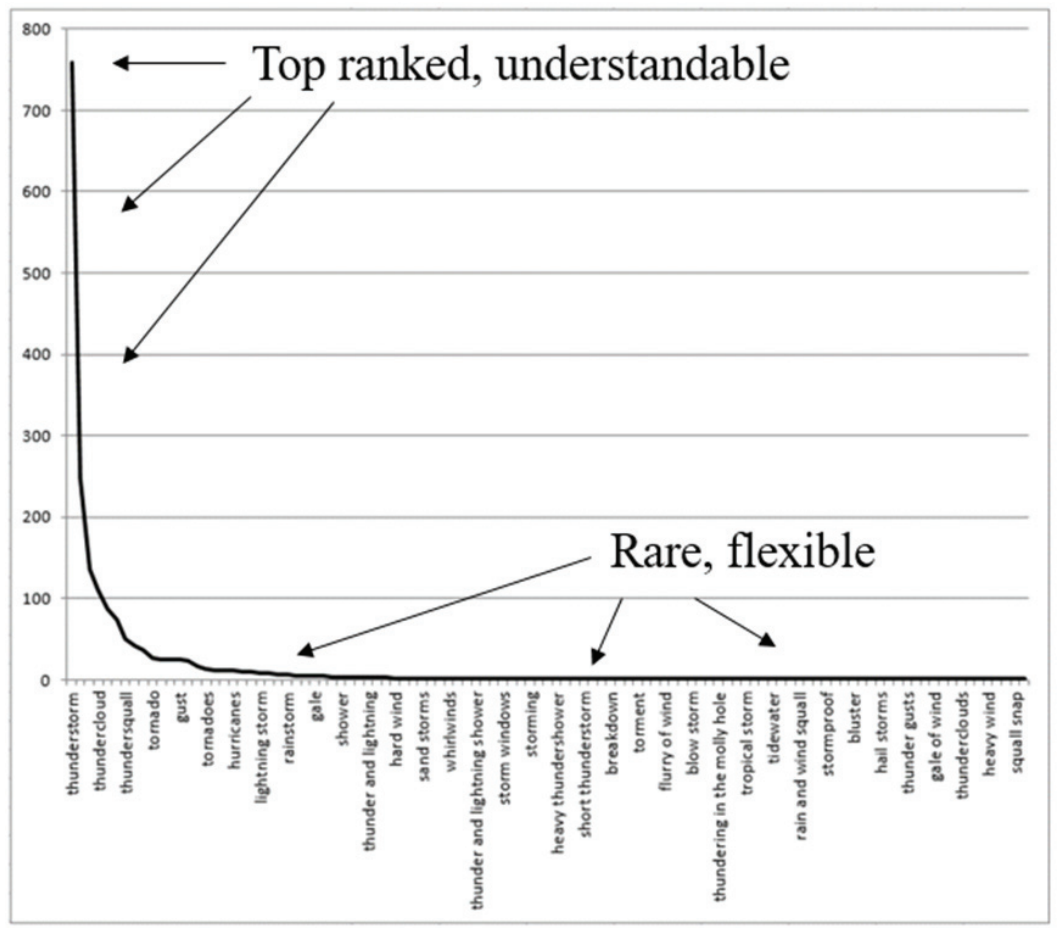

Figure 7: How we use the A-curves in language

As Figure 7 suggests, we can feel right about the language of writing in a particular domain because of the top ranked words, whether it is academic writing or fiction, whether academic writing in general or academic humanities. We expect to see these common words and our expectations are validated when we do see them. We understand the discourse better, we find it more coherent, when the words that we expect to see are present. However, the top-ranked words are not the only ones present: we have the full range of the lexicon available to make our writing in the domain flexible and precise and our own. We need to have both sides of the curve, the very frequent words and the long tail of less frequent words, in order to be able to write what we need to say and in order to make our discourse coherent. The same thing happens with our use of function words and content words: the highly frequent function words create coherence in the discourse, while the less frequent content words make the writing flexible and pre- 
cise. The organization of the lexicon into scale-free domains with nonlinear frequency profiles for the lexicon in each domain makes this possible.

Word frequency is not the only dimension in which the A-curve pattern occurs. We can also see it when words are used together in running text: collocations. As corpus linguists will remember the words of John Sinclair, "Complete freedom of choice ... for a single word is rare. So is complete determination" (2004: 29). We have already seen the frequency patterns of words in different domains of speech and writing. Observation of the co-occurrence of words in writing and speech yields similar patterns. Let us consider three words that a thesaurus will say are synonyms: big, large, and sizable. Figure 8 shows that the top twenty noun collocates of big in the COCA corpus follow the same A-curve pattern as the frequency profile of words in domains.

\begin{tabular}{|c|c|c|c|c|c|c|c|}
\hline HELP & ? & & FREQ & ALL & $\%$ & MI & \\
\hline 1 & $\square$ & DEAL & 19276 & 208687 & 9.24 & 4.60 & 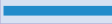 \\
\hline 2 & $\square$ & DIFFERENCE & 5185 & 116107 & 4.47 & 3.56 & 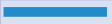 \\
\hline 3 & $\square$ & BANG & 4313 & 13677 & 31.53 & 6.38 & $=$ \\
\hline 4 & $\square$ & PICTURE & 4291 & 110445 & 3.89 & 3.36 & $\square$ \\
\hline 5 & $\square$ & BROTHER & 4148 & 118703 & 3.49 & 3.20 & 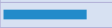 \\
\hline 6 & $\square$ & FAN & 4136 & 48526 & 8.52 & 4.49 & 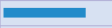 \\
\hline 7 & $\square$ & MISTAKE & 2954 & 50717 & 5.82 & 3.94 & 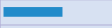 \\
\hline 8 & $\square$ & SCREEN & 2686 & 67833 & 3.96 & 3.38 & 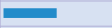 \\
\hline 9 & $\square$ & BUCKS & 1742 & 20704 & 8.41 & 4.47 & 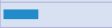 \\
\hline 10 & $\square$ & BANKS & 1738 & 50714 & 3.43 & 3.17 & $=$ \\
\hline 11 & $\square$ & LEAGUES & 1389 & 6768 & 20.52 & 5.76 & $\square$ \\
\hline 12 & $\square$ & BIRD & 1349 & 38464 & 3.51 & 3.21 & - \\
\hline 13 & $\square$ & CORPORATIONS & 1078 & 23186 & 4.65 & 3.61 & 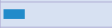 \\
\hline 14 & $\square$ & CHUNK & 863 & 6799 & 12.69 & 5.06 & - \\
\hline 15 & $\square$ & HUG & 837 & 12769 & 6.55 & 4.11 & $=$ \\
\hline 16 & $\square$ & TOE & 647 & 9276 & 6.97 & 4.20 & E \\
\hline 17 & $\square$ & TENT & 550 & 15285 & 3.60 & 3.24 & E \\
\hline 18 & $\square$ & $\mathrm{OL}$ & 547 & 6488 & 8.43 & 4.47 & 口 \\
\hline 19 & $\square$ & PHARMA & 499 & 1712 & 29.15 & 6.26 & 口 \\
\hline 20 & $\square$ & BELIEVER & 416 & 6269 & 6.64 & 4.13 & - \\
\hline
\end{tabular}

Figure 8: COCA top 20 noun collocates of big

Big deal is over twice as common as the second-ranked form, big difference. The frequencies of the ranks after that descend more gradually. 


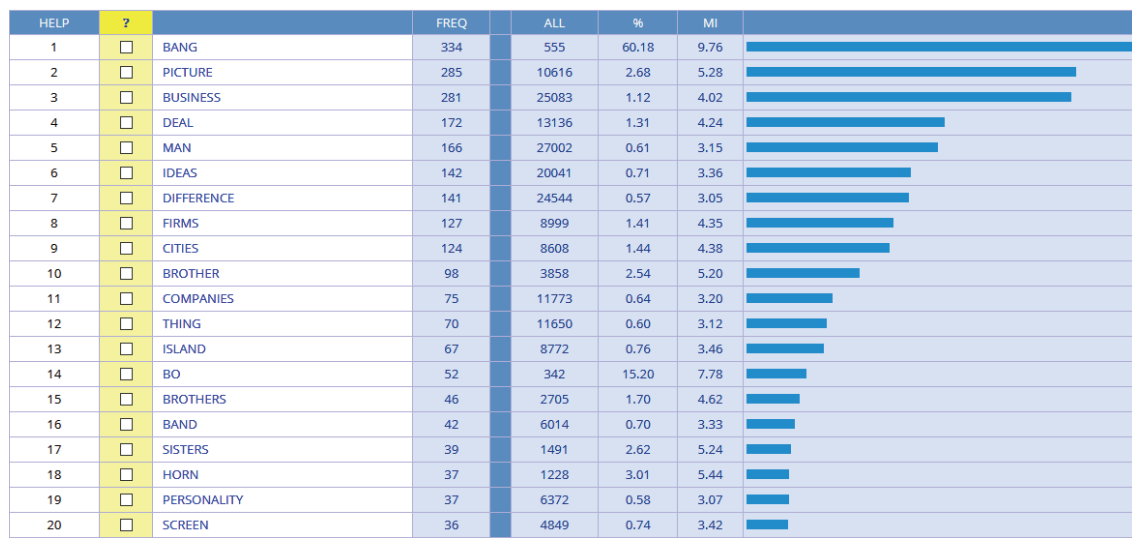

Figure 9: Top 20 noun collocates of big, COCA Academic

Figure 9 shows the top twenty noun collocates of big just in the COCA academic writing section, and again we find the same A-curve for the frequency profile of collocates. And again, we see that the list of words is not identical to the overall list of collocates for big and that the words are in a different order (deal, for example, is now only the fourth most common noun collocate, proportionately only about 50 percent of what it was for the overall list). We are observing the underlying organization of words in a corpus in a different way, now in another dimension, the collocates of particular words. It is clearly not the case that a word like big just modifies random nouns. We use the word in characteristic situations, with difference and brother in the overall corpus and with bang and man in academic writing, with deal, business, and picture in both. As for word frequency profiles in different domains, the language sounds right to us if we encounter words used with the right collocates, either in general or in specific domains. We find such usages to be coherent. Of course, the word big can also be used with a great number of other nouns, which allows the language to be flexible and precise and our own.

The possible synonym of big, the word large, has a different list of collocates. 


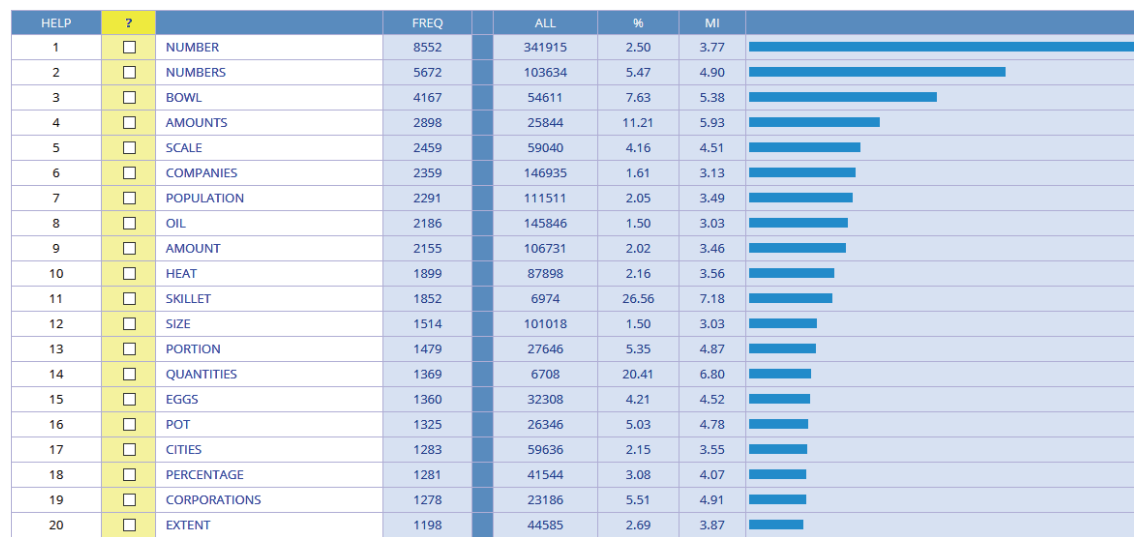

Figre 10: COCA top 20 noun collocates of large

Figure 10 shows that the list of the top twenty noun collocates for large in COCA carries over only one word from the big list (corporations), and this word is in different places on the A-curve (rank 13 vs rank 19) It would be difficult to maintain that large and big are really synonyms when we have quite different characteristic uses for them. What about sizable? Figure 11 shows that the list of the top twenty noun collocates for sizable in COCA carries over only one word from the big list (chunk), and only seven words from the list for large (number, numbers, chunk, population, portion, amount, percentage). Only one word occurs on all three collocate lists: chunk. Again, it would be difficult to insist that the three words are really synonyms, when they share so few of their top twenty collocates. Of course, large and sizable can be used with a great many more nouns than those in their top collocate lists, which makes the language flexible and precise, but the use of all three of our size words with characteristic A-curves of collocates gives the language understandability and coherence. As Sinclair (2004:29) told us, the meaning of single words is strongly constrained by frequent co-occurrence with other words, and not just in fixed phrases (idioms). We all use the frequency profiles of the language, for words in domains and for words used together, as a basic, reliable component of our linguistic interactions. 


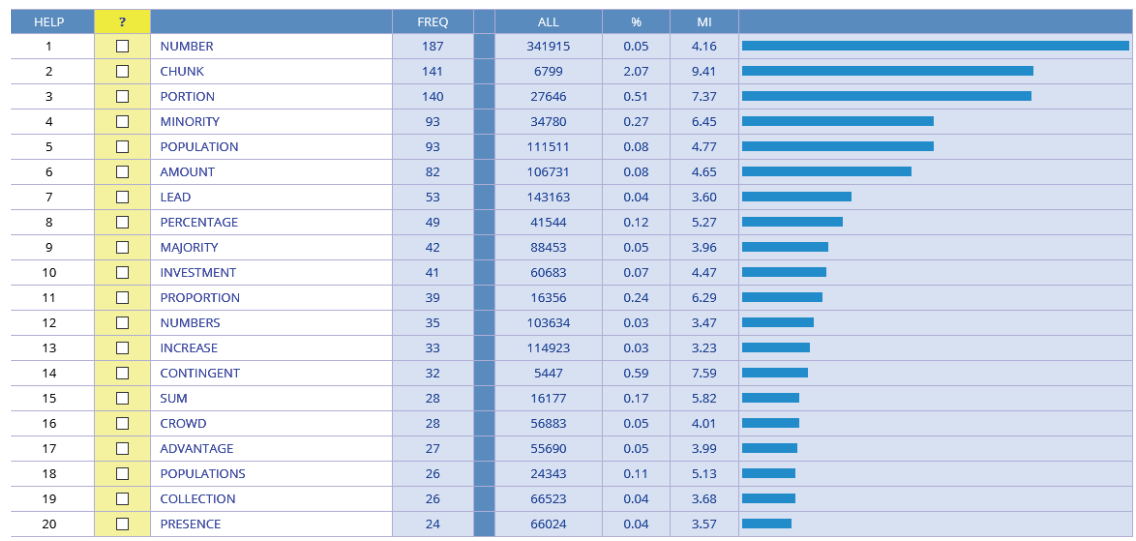

Figure 11: COCA top 20 noun collocates of sizable

This scale-free self similarity is not limited to words and collocates. As I have shown elsewhere (Kretzschmar 2009, 2015, 2018), we see it in word variants in linguistic surveys across areas and social groups, and in pronunciations of words. Scale-free self similarity is a property of every linguistic feature that we care to recognize. It is characteristic of human speech in every language at least in each one of the many languages that my students have studied. As a consequence of linguistic interactions between people, how could it not be? Indeed, the scaling property that carries such frequency profiles down to individual users of language also carries it up to the largest possible group of people. One implication of the complex systems model is that, at the highest level, there is only one language, the human language, and that what we perceive as different languages and varieties of languages are just subdivisions of the whole.

To return to the problem of statistics raised at the beginning of the essay, the kind of statistics we have been taught is a poor match for the fractal mathematics of language. 


\section{- Bell curve (Gaussian): A-curve (nonlinear): \\ - Central tendency

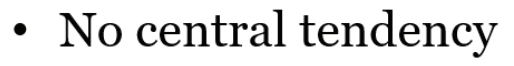

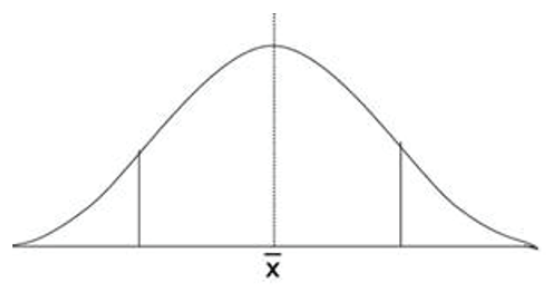

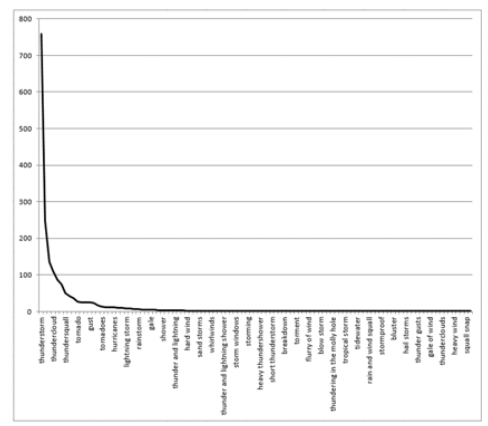

Figure 12: Normal vs. nonlinear distributions

Gaussian statistics are based on the normal distribution, the bell curve, which has a central tendency, the mean, as shown at left in Figure 12. Modern statistics are based on the idea that, in such a curve, it is possible to say how many observations are close to the mean so that, if an observation is well away from the mean we know that it is 'significant,' and we are entitled to ask why it is different. For a fractal distribution there is no central tendency; we just know that a few observations occur very frequently, some observations are moderately common, and most observations are rare. If we apply Gaussian statistics to the Acurve, the mean value will always be too low because of the long tail of the curve, and the standard deviation from the mean and the overall variance of the curve will be much too high. Curve-fitting with the Lorenz Curve and Gini Coefficient (Kretzschmar 2015: 180-184) shows that normal distributions are generally distinguishable from nonlinear ones. A statistic based on the bell curve will only work on language data if we cut off the top-ranked features and those in the long tail, which is what many linguists have done. Any features that occurred more than 80 percent of the time or less than 20 percent of the time are simply not testable with a Gaussian statistic (see also Koplenig 2019). The practice in linguistics has not been different from the statistical practice in economics, where most economists try to make their nonlinear data look more Gaussian, and ongoing events in the world economy have shown us how well that works. 
The mismatch of assumptions for use of Gaussian statistics on language data in corpora means that we cannot use inferential statistics, those that claim significant results based on z-scores. We can, however, continue to use Mutual Information (MI) scores and nonparametric statistics like chi square and log likelihood. This means that our usual measures of comparison between a reference corpus and a target corpus can still be used with care. The picture is less clear for Black Box methods. Douglas Biber, for example, have been very successful with register analysis using multi-dimensional analysis (Biber 2019, Egbert, Larsson, and Biber 2020), a Black Box method. Clusters of variants are taken to define registers. The success of the method comes from the choice of particular variants that have different frequencies in different groups of texts, represented with decimal numbers with + and - signs which conceal raw frequencies. While the use of multi-dimensional analysis has been influential in corpus studies, and it is quite clear that different registers can be characterized by different linguistic properties, it has been less clear why this is so. CS offers a sufficient explanation for why and how different aspects of linguistic variation can help us to explain the difference in linguistic practice between different text types.

It is possible to avoid the Black Box and to use raw frequencies more directly. As shown in Kretzschmar and Coats (2018), comparison of frequencies between two corpora cannot rely just on the magnitude of the quantitative difference. Figure 13 compares the rate of occurrence of the word said in Hemingway's A Farewell to Arms (at left) against the Brown Corpus (at right). 

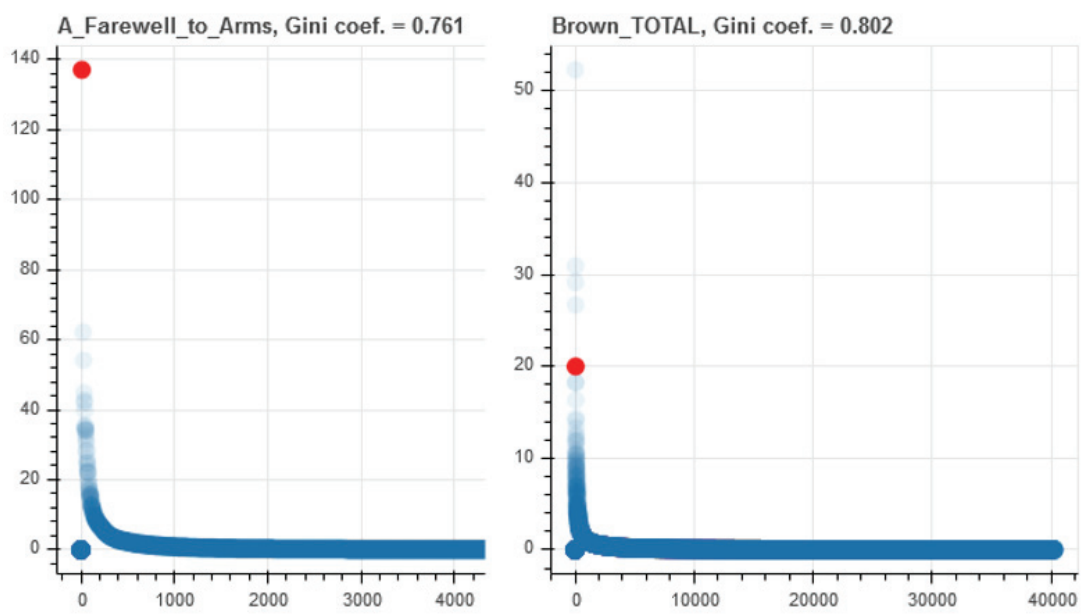

Figure 13: said: A Farewell to Arms vs the Brown Corpus

There is a large quantitative difference between the rates, which creates a large $\log$ likelihood number in the keyness metric of tools like AntConc or WordSmith Tools. However, the placement of said on the two A-curves is in the same location, on the ascender, so that the degree of quantitative difference does not make a difference in the status of the word: it is a top-ranked word in both cases. The situation is different for the word darling in Figure 14. 

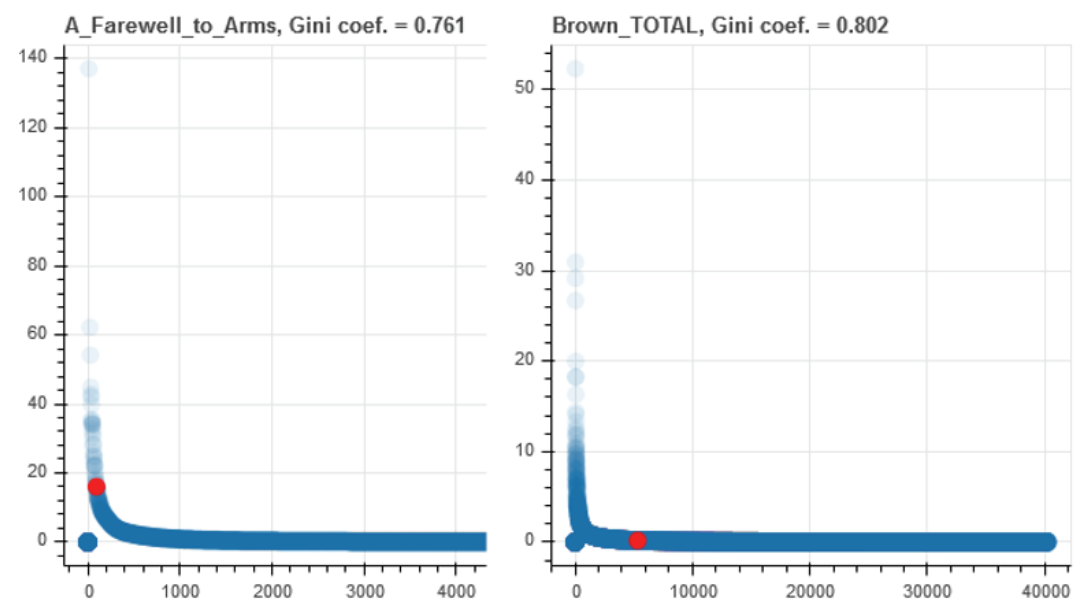

Figure 14: darling: A Farewell to Arms vs the Brown Corpus

In this case the raw quantitative difference in rates is smaller than it is for said, but darling is in the ascender of the curve in Hemingway's novel while it is in the long tail in the Brown Corpus. The word is among the top-ranked words for Hemingway but not in Brown, so its condition has essentially changed. We can say that it is a Hemingway word, or a special word for this novel at least. We cannot say the same for said, although a word like said does belong more to the narrative text type of a novel as compared to the range of text types in Brown. This is a key finding because it shows that quantitative degree of frequency is not the only thing we need to know in a comparison of corpora - and thus Black Box methods that may use it will not be entirely satisfactory. We can observe what comes down to a change in the state of a word (or collocate) on the Acurves, which appears to be more important. By analogy, the difference in status on either side of the hyperbolic bend in the A-curve corresponds to a historical change in language, since the S-curve taken to represent change in language is just a transformation of the A-curve to show one variant over time rather than all the variants at one time (Kretzschmar 2015: 112-121). Thus, the comparisons that corpus linguists habitually use can still be used in a CS approach, and the CS method of assessment of quantitative differences is more subtle than other existing methods. 
The scale-free property of the CS model justifies the fine attention to text types practiced by corpus linguists. There is a top-level generalization about a language to be made, historically the only one made by NLP practitioners, but the CS model asserts that there is an unlimited number of other, smaller scales in a language. Thus, it is reasonable to try to make a high-level reference corpus like the Brown Corpus or the BNC Corpus or COCA (to go from small to large), and at the same time segregate such a corpus into smaller pieces, like the fifteen subsections of the Brown Corpus and the initial five subsections of COCA that can be further subdivided into smaller subsections (as illustrated above). The idea of 'the more the better' from NLP research is undercut by the demand in CS for deliberate, detailed sampling, because every imaginable subsection will have its own frequency profile: without knowing exactly what group of texts or speech is being sampled, we cannot make useful generalizations. Thus we cannot say that darling is a Hemingway word if we have only used $A$ Farewell to Arms as our sample. We know the status of the word in the novel, but its status for Hemingway is speculation unless we create an appropriate sample including more of his work. The different scales of analysis offered by CS do not have necessary relations, either part to whole or whole to part. The error of trying to generalize from a small subsection to a larger one is called the "individual fallacy," and from a large subsection to a smaller one the "ecological fallacy," in Horvath and Horvath (2001, 2003). Random sampling and accurate designation of the group to be sampled are thus extremely important for corpus linguists.

Corpora, according to the CS model, are highly organized according to frequency profiles of where and how the words are used. The fact that people use words in this way is part of what we learn about our language, as we experience the language of speakers and writers around us. We learn it for the first time in our elementary language acquisition, and we continue to learn about new domains of use - like how to write papers in different university majors, or how to negotiate business deals - for the remainder of our linguistic lives. The fact that we have not realized that frequency distributions play such a large role (or should I say big role? or sizable role?) in how we use language comes from our traditional preoccupation with other aspects of language in schools and in linguistics, with grammars and dictionaries. However, now that we know about the organization of language use in corpora by frequency profiles, we would be well advised to integrate it with our other ideas about language and corpora. 


\section{Acknowledgements}

I would like to thank the editors Merja Kytö and Anna-Brita Stenström and an anonymous reviewer for their helpful comments on an earlier version of this paper. All remaining shortcomings are entirely my own.

\section{References}

Burkette, Allison. 2016. Language and material culture: Complex systems in human behavior. Amsterdam: John Benjamins.

Burrows, John. 2008. Textual analysis. In S. Schreibman and R. Siemens (eds.). A companion to digital humanities. Oxford: Wiley-Blackwell. Viewed online at digitalhnumanities.org:3030/companion.

Biber, Douglas. 2019. Text-linguistic approaches to register variation. Register Studies 1: 42-75.

Bybee, Joan. 2001. Phonology and language use. Cambridge: Cambridge University Press.

Bybee, Joan. 2002. Sequentiality as the basis for constituent structure. In T. Givón and B. F. Malle (eds.). The evolution of language out of prelanguage, 109-132. Amsterdam: Benjamins.

Bybee, Joan. 2010. Language, usage and cognition. Cambridge: Cambridge University Press.

Corpus of Contemporary American English (COCA). Viewed at http://corpus.byu.edu/coca/.

Egbert, Jesse, Tove Larsson and Douglas Biber. 2020. Doing linguistics with a corpus. Cambridge: Cambridge University Press.

Ellis, Nick and Diane Larsen-Freeman (eds.). 2009. Language as a complex adaptive system. Oxford: Wiley-Blackwell.

Gould, Stephen Jay. 2003. The hedgehog, the fox, and the magister's pox: Mending the gap between science and the humanities. New York: Three Rivers.

Hawking, Stephen and Leonard Mlodinow. 2010. The grand design. New York: Bantam.

Holland, John. 1998. Emergence: From chaos to order. New York: Basic.

Hopper, Paul. 1987. Emergent grammar. Berkeley Linguistics Society 13: 139157. (Viewed at http://home.eserver.org/hopper/emergence.html) 
Horvath, Barbara M. and Ronald J. Horvath. 2001. A multilocality study of a sound change in progress: The case of $/ 1 /$ vocalization in New Zealand and Australian English. Language Variation and Change 13: 37-58.

Horvath, Barbara M. and Ronald J. Horvath. 2003. A closer look at the constraint hierarchy: Order, contrast, and geographical scale. Language Variation and Change 15:143-170.

Koplenig, A. Against statistical significance testing in corpus linguistics. Corpus Linguistics and Linguistic Theory 15: 321-346.

Kretzschmar, Jr., William A. 2008. Neural networks and the linguistics of speech. Interdisciplinary Science Reviews 33: 336-356.

Kretzschmar, William A., Jr. 2009. The linguistics of speech. Cambridge: Cambridge University Press.

Kretzschmar, William A., Jr. 2015. Language and complex systems. Cambridge: Cambridge University Press.

Kretzschmar, William A., Jr., and Steven Coats. 2018. Fractal visualization of corpus data. A paper given at the ICAME 39 conference. Tampere, Finland.

Langacker, Ronald. 1988. A usage-based model. In Brygida Rudzka-Ostyn (ed.). Topics in cognitive linguistics, 127-161. Amsterdam: John Benjamins.

Lindblom, Bjorn, Peter MacNeilage and Michael Studdert-Kennedy. 1984. Selforganizing processes and the explanation of phonological universals. In B. Butterworth, B. Comrie and O. Dahl (eds.). Explanations for language universals, 181-203. New York: Mouton.

Mandelbrot, Benoit. 1982. The fractal geometry of nature. San Francisco: Freeman.

Mitchell, Melanie. 2009. Complexity: A guided tour. Oxford: Oxford University Press.

Prigogine, Ilya and Isabelle Stengers. 1984. Order out of chaos. Man's new dialogue with nature. New York: Bantam Books.

Sinclair, John. 2004. Trust the text. London: Routledge.

Thelen, Esther and Linda Smith. 1994. A dynamic systems approach to the development of cognition and action. Cambridge: MIT Press. 